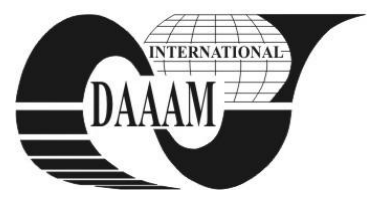

\title{
INTELLIGENT CONTROL AND MONITORING OF DRINKING WATER DISTRIBUTION SYSTEM
}

\author{
EGRI, A[ngela]; SIRB, V[ali] C[hivuta]; PATRASCOIU, N[icolae] \& TOMUS, A[drian]
}

\begin{abstract}
Our goal was to create an original knowledge-based intelligent software application for control and monitoring of drinking wate distribution system implemented and experimented for three cities from Jiu Valley region. For this purpose we created an knowledge-based intelligent systems for control and monitoring the parameters referring to the raw water catchment stations and the measuring instruments as: water turbidity, valves' state, the flow on the loading tank', the drinking water level in the tanks and the pressure at the customers The knowledge-based intelligent control and monitoring system was implemented in the Visual Basic programming language which is a high productivity development environment, a visual development software, object orientated, ideal for this type of applications, processes simulations control and monitoring.
\end{abstract}

Key words: knowledge, knowledge base, intelligent control, monitoring

\section{INTRODUCTION}

The high complexity of the drinking water distribution systems and the necessity to monitor the parameters reffering to the raw water catchment stations as well as the measuring instruments as: water turbidity, valves' state, the flow on the loading tanks', the drinking water level in the tanks and the pressure at the customers, impose intelligent monitoring well mathematical based solutions and concretized by the conceiving of the knowledge-based intelligent systems (Egri A, 2002) for control and monitoring. Within this work we present our software solution for intelligent control and monitoring conceived and experimented for three cities.

\section{THE GRAPHICAL INTERFACE OF THE KNOWLEDGE BASED INTELLIGENT SYSTEM}

The graphical interface of the monitoring system was implemented in the Visual Basic programming language which is a high productivity developpement environment,(Cosma $\mathrm{E}$, 2005) a visual development software, object orientated, ideal for this type of applications, processes' simulations control and monitoring. The main working window of the graphical interface contains 8 menues (fig 1) namely "The problem" (1), "The Factual base"(2), "Knowledge base"(3), "Process simulation"(4), "Knowledge system based intelligent simulation"(5), "Knowledge based intelligent system"(6), "About" (7) and "Exit"(8).

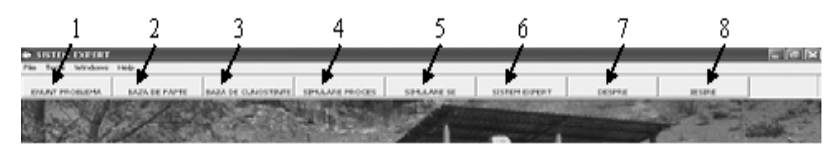

Fig. 1. The menues of the graphical interface

On activating the "the problem" menu a window opens (fig. 2) which dispalyes "intelligent system for control and monitoring" which is, in fact, the problem to be solved.

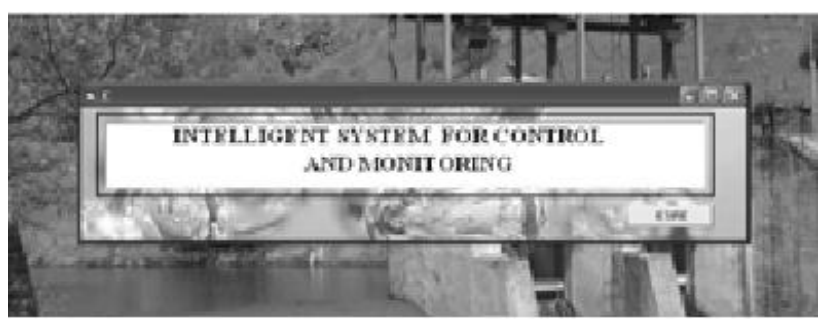

Fig. 2. "The Problem" window

\section{PROCESS SIMULATION}

By accessing the „process simulation” menu, running simulation window will open (fig. 3) of the drinking water distribution system. The state of each element is determined by a ,if-then" rule.The process elements are the following: the Catching, Filtering and Treating Station 1(CFTS1), the Dreans 1 together with the Catching, Filtering and Treating Station 2(CFTS2), the turbidimeter TBM, the valves: VTJ, VTT, VT3, VT33, VT1, VT11, VT0, VT5, VT2, VT22, VT4, VT44, the flow sensors: TD0, TD1, TD2, TD3, TD4, the $500 \mathrm{~m}^{3}, 3000 \mathrm{~m}$ ${ }^{3}, 1000 \mathrm{~m}^{3}, 2500 \mathrm{~m}^{3}$ and $4000 \mathrm{~m}^{3}$ tanks, the level sensors: TN0, TN1, TN2, TN3, TN4, the pressure sensors: TP1, TP2, TP3, TP4 and the consumers: C1(upper-town of city 1), C2(down-town of city 1), C3(city 2) and C4 (city 3).

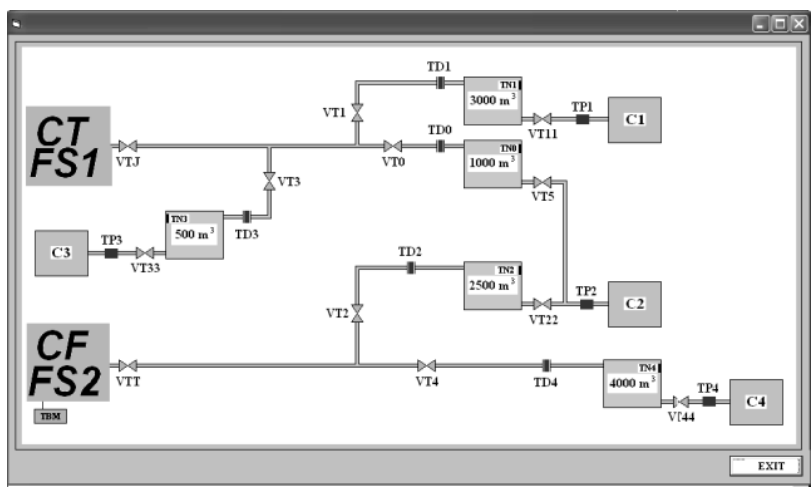

Fig. 3. The process simulation window

\section{THE FACTUAL BASE}

The factual base comprises the initial facts and the intermediate results produced along the deduction procedure. The facts are represented using the conventional knowledge representation and the adequate mathematical formalism.

By accessing the "FACTUAL BASE" menu a window opens, shown in figure 4 which comprises the factual base, 
which comprises all the possible facts of the monitorised process (fig. 3), the block-diagram of the system comprising the following compounding elements: the Water Catchment 1, Filtering and Treating Station 1, the Catchment 2, Filtering, Water Treating Station 2, the dreans, the turbidity measuring instrument, valves, the flow sensors, 5 tanks of different volumes, level sensors, pressure sensors and the consumers.

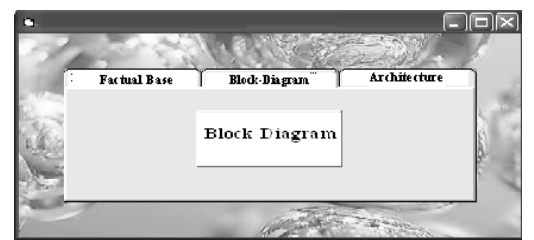

Fig. 4. The factual base window

As we may observe, the considered water distribution system in the city 1 , has two raw water catchment stations ensuring, after the filtering and treating process, the load of all the consumers connected to the drinking water network. The C1, C2, C3 blocks respectively $\mathrm{C} 4$ represent the consumers covering the upper-town of city 1 , the down-town of city 1 , city 2 and city 3 (fig. 3 ) and the architecture of the intelligent realised system (fig. 5).

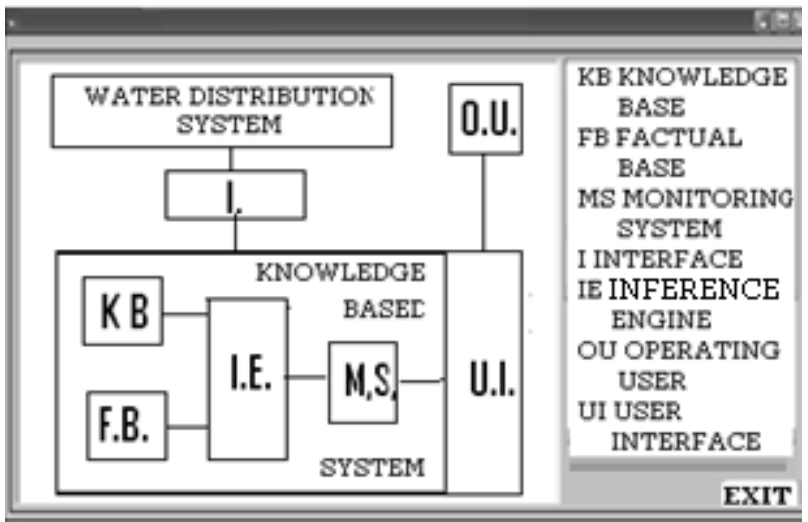

Fig. 5. The architecture of the knowledge-based system

\section{THE KNOWLEDGE BASE}

The knowledge base is made up by the assembly of all the specialised knowledge introduced by the human expert. The knowledge stored here are mainly the descriptions of the objects and the relations between them. The knowledge base is part of the cognitive system, knowledge being memorised in a special organised space.

The access to the knowledge base of the intelligent system is restricted for security reasons and is made by a username and a password. So, we avoid unauthorised users' access to the knowledge base which can affect the data integrity. The knowledge base window contains lines in which we can identify 7 fields: ID: text type, TBM: text type , VT: text type, TD: text type, TN: text type, TP: text type and SOLUTION: text type. The extended knowledge base of the intelligent system has a menu with which's help we can take the following actions: adding the data to the existing knowledge base, erasing the data from the existing knowledge base, the expansion of the existing knowledge base by adding a new field named „PARAMETER” and selecting its type, canceling the extension of the knowledge base by eliminating the "PARAMETER" field, adding the „SOLUTION" named field after the knowledge base was extended by introducing the field named „PARAMETER”, erasing the field named „SOLUTION”, adding data in the extended knowledge base, erasing data from the extended knowledge base and outgoing/ exitting this window.

Each rule may be selected or not by marking or not the attached four-square (fig. 6). So we have the possibility to choose more combinated situations.

\begin{tabular}{|c|c|c|}
\hline The tubidity is greater than 65 NTU? & 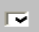 & \\
\hline Are the valves opened? & $\Gamma$ & \\
\hline Are the tank bad flows sufficent? & ᄃ & YES NO \\
\hline Are the water levels in the tanks sufficent? & 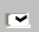 & $\sqrt{2}$ \\
\hline Are the consumers' pressures sufficient? & $\Gamma$ & \\
\hline
\end{tabular}

Fig. 6. The rules window

\section{THE IMPLEMENTED KNOWLEDGE-BASED SYSTEM FOR CONTROL AND MONITORING}

By accessing the "Knowledge-based Intelligent SYSTEM" menu it opens the control and monitoring window (fig. 7), which will deliver the current case's afferent solution.

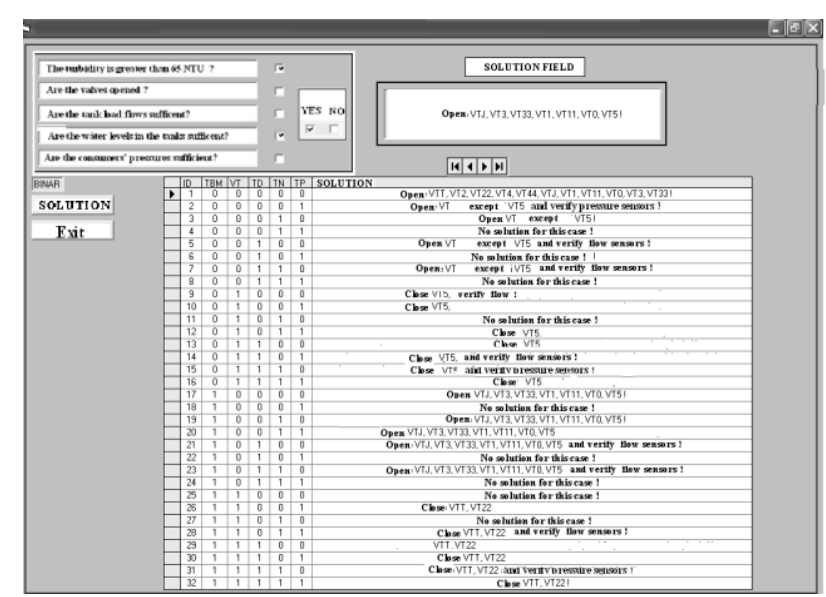

Fig. 7. The control and monitoring window

\section{CONCLUSION}

This knowledge-based intelligent software application resolve with high fidelity the control and monitoring problem of the parameters reffering to the raw water catchment stations as well as the measuring instruments as: water turbidity, valves' state, the flow on the loading tanks', the drinking water level in the tanks and the pressure at the customers of drinking water distribution system.

Runnig quickly and ofer very good control and monitoring solutions.

The knowledge-based intelligent software application for control and monitoring of drinking water distribution system was implemented and experimented for three cities from Jiu Valley region.

The software application can be extended to a larger area, more than one region or country what we want to do in the future.

\section{REFERENCES}

Alexandru, A.; (2002). Expert systems. Concepts and aplication, Publishing Matrix Rom, ISBN 973-685-226-1, Bucharest, Romania

Benchimol, G. ; Levine, P. \& Pomerol; (1993). Expert systems in the manufactures, Technical Publishing, ISBN 973-31-0471-X, Bucharest, Romania

Cosma, E.; (2005). Visual Basic.VBA 2007. Studio, Publishing Matrix Rom, ISBN 978-973-755-233-4, Bucharest, Romania

Egri, A.; (2002). Artificial intelligence and robotic, Focus Publishing, ISBN 973 -8367 - 48 - 4, Petrosani, Romania

***Whitby, B.; (2003). Artificial intelligence, Oneworld Publications, ISBN 1851683224, London, England 